\title{
ROGELIO SALMONA Y LA ARQUITECTURA CON LADRILLO EN COLOMBIA
}

\author{
(ROGELIO SALMONA AND BRICKWORK ARCHITECTURE IN COLOMBIA)
}

\section{Josep $\mathrm{M}^{\mathrm{a}}$ Adell}

Profesor, Doctor Arquitecto. Universidad Politécnica Madrid (UPM). Dpto. Construcción y Tecnología Arquitectónicas (DCTA). Escuela Técnica Superior de Arquitectura (ETSAM). Director Línea Investigación sobre fábricas en el Grupo de Investigación de Tecnologías Innovadoras y Sostenibles en Edificación (TISE-fábricas). Presidente del $12^{\text {th }}$ IBMAC 2000.

Fecha de recepción: 2-I-05

ESPAÑA

\begin{abstract}
RESUMEN
La obra del colombiano Rogelio Salmona, se fundamenta en la cultura europea, y desarrolla las posibilidades del ladrillo de calidad que se fabrica en su país.
\end{abstract}

El Arquitecto emplea el ladrillo con maestría en todas las disposiciones espaciales posibles, paredes, suelos y techos, articulando, en todos los casos, sabias composiciones constructivas, surgidas de su propia experiencia y evolución a lo largo de los años con este material cerámico.

Para rematar adecuadamente sus edificaciones, privadas y públicas, Salmona ha diseñado dos piezas especiales (tipo jamba y tipo vierteaguas) con las que obtiene múltiples acabados que dignifican su composición y funcionalidad arquitectónica, utilizando siempre como mínimo, muros de 1 pie de grueso.

Sus obras de viviendas como las Torres del Parque en Bogotá y los edificios públicos como la Casa de Huéspedes Ilustres de Colombia, o el Archivo General de la Nación, han merecido calificar a este Arquitecto como uno de los más destacados de la Arquitectura hispanoamericana, ganando con ello múltiples reconocimientos.

\section{SUMMARY}

The oeuvre of Colombian Rogelio Salmona borrows heavily from European culture while developing the potential of the high quality brick manufactured in his country.

Salmona exhibits a masterful command of the use of brick in all possible spatial arrangements -walls, floors and ceilingsalways articulating sound constructional compositions based on his many long years of experience with this ceramic material.

The two pieces (jamb-type and dripstone-type) specially designed by the architect for his buildings are used to create multiple finishes that dignify their architectural composition and functionality, with walls that are always at least one foot thick.

His housing projects such as "Torres del Parque" in Bogotá and public buildings such as the "Home of Colombia's Distinguished Guests" or the headquarters for the General National Archives have earned him renown as one of Latin America's most outstanding architects, as well as any number of honours and distinctions.

\section{INTRODUCCIÓN}

Colombia, es un país que se caracteriza por tener una climatología bastante homogénea, de días tropicales con igual duración diurna que nocturna, variando ligeramente en las épocas de lluvia y de sequía. A todo ello hay que añadirle la típica humedad ambiente tropical, que requiere de mucha ventilación para poder soportar las elevadas temperaturas.
Por otra parte, en Colombia, hay una abundante tradición de construcción en ladrillo, con fábricas que hacen ladrillos cerámicos prensados de gran calidad. El ritmo del tiempo en este país, más sosegado que en otros, ofrece al arquitecto, la posibilidad de dedicar tiempo al proyecto y tiempo a la construcción de forma diferenciada y sin llegar a solaparse, lo que le permite recrear en la propia obra, la edificación hasta afinarla en sus aspectos constructivos más pormenorizados. 
Bajo este planteamiento, Rogelio Salmona es capaz de controlar no sólo la preparación de las recetas de sus proyectos, sino también el tiempo y grado de cocción o madurez durante el desarrollo de las obras.

La consecuencia de todo ello es el logro de una edificación "total" donde nada queda a la improvisación del constructor, ya que el Arquitecto actúa también a pie de obra durante la fase de ejecución, hasta lograr la perfección de la edificación.

\section{ETAPA DE FORMACIÓN EUROPEA}

Rogelio Salmona destaca por tratarse de un Arquitecto hispanoamericano formado en el movimiento moderno surgido en Europa.

Son múltiples los viajes que este autor ha realizado a las ciudades europeas, dibujando e interpretando de primera mano tanto la arquitectura popular como la de las ciudades históricas, destacando en ellas su aspecto urbanístico, lo que sin duda influyó en su capacidad espacial de organizar la arquitectura de la ciudad (Fig. 1).

También es conocida su relación profesional con Le Corbusier, de cuyas fuentes arquitectónicas se impregna para desarrollar después su original arquitectura, basada en las pautas y maestría de su creador.

\section{LAS VIVIENDAS SOCIALES}

Son múltiples las viviendas de distinto nivel económico que Rogelio Salmona ha desarrollado en su país, tanto a nivel de viviendas individuales como agrupadas en grandes edificios, mancomunidades, o rascacielos.

Entre las viviendas individuales, destacamos la Casa Alba en Bogotá, donde el ladrillo viste las paredes y los suelos del edificio de una planta y la teja conforma el plano de cubierta, creando un ambiente de homogeneidad de materiales (Fig. 2).

Este planteamiento del dominio del paramento de ladrillo cara vista, se extiende en los muros medianeros, que quedan manifiestos en el conjunto multifamiliar de la Fundación Cristiana de San Pablo para la vivienda (1963) (Fig. 3).

Sin embargo, donde realmente Salmona consigue diseminar a lo largo, ancho y alto del espacio, el lenguaje del ladrillo en la edificación de viviendas, es en las Torres del Parque de finales de los 60, que circundan la plaza de Toros de Bogotá, realizada en su día con arquitectura neomudéjar, sin duda inspirada en la Plaza de Toros de Rodríguez Ayuso y Álvarez Capra construida en 1874 y que dio pie al inicio de la Arquitectura de ladrillos del siglo XIX madrileña (Fig. 4).

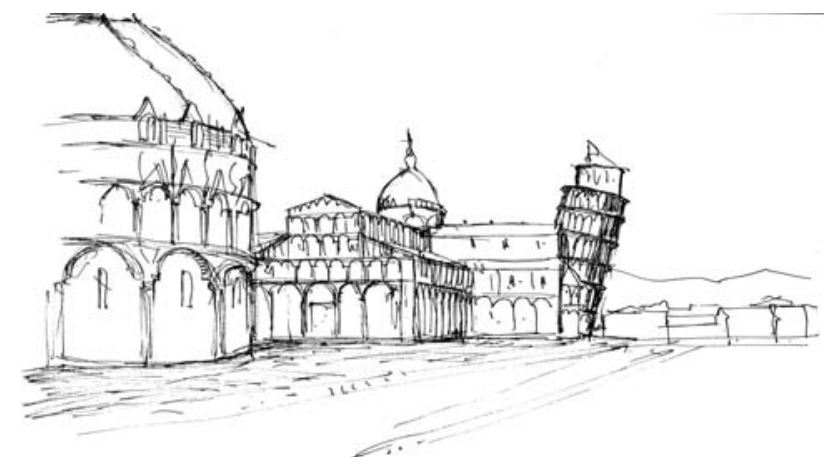

Figura 1.- Pisa, Torre y Baptisterio, dibujo de Salmona (1951).

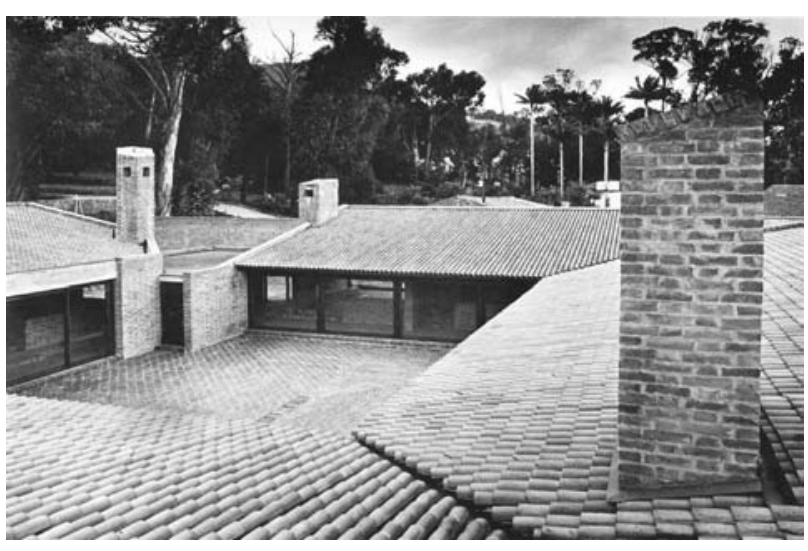

Figura 2.- Casa Alba (Bogotá), paredes y suelos de ladrillo, y cubiertas de teja.

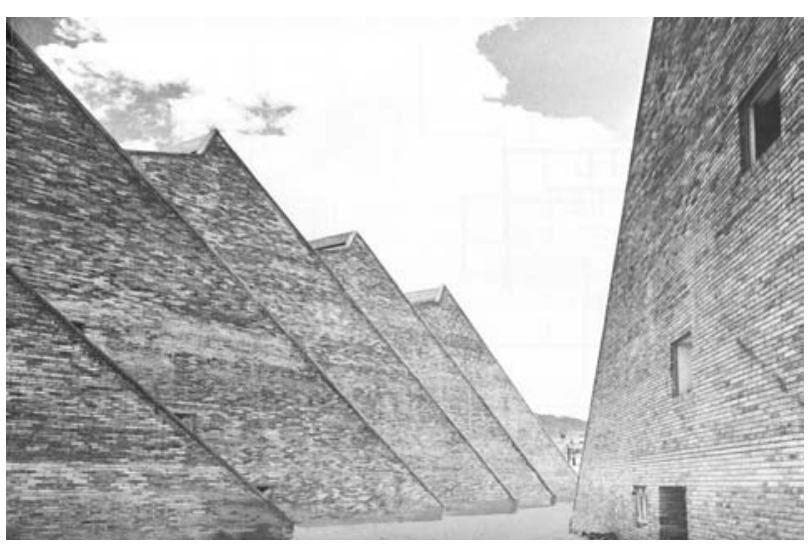

Figura 3.- Escalonado de muros piñones medianeros de ladrillo cara vista, del conjunto multifamiliar de la Fundación Cristiana de San Pablo para la vivienda (1963).

El conjunto residencial de 294 viviendas se constituye en 3 torres de planta sensiblemente semicircular, que se desarrollan siguiendo un orden helicoidal basado en los ejes estructurales que, como resultado, ofrecen una fachada de planta endentada, donde los paños de ladrillo se articulan entre sí con un sutil engranaje de los mismos en el encuentro de un paño con otro, si bien queda a la vista el frente del forjado volado donde apoya el ladrillo (Fig. 5.a y b). 


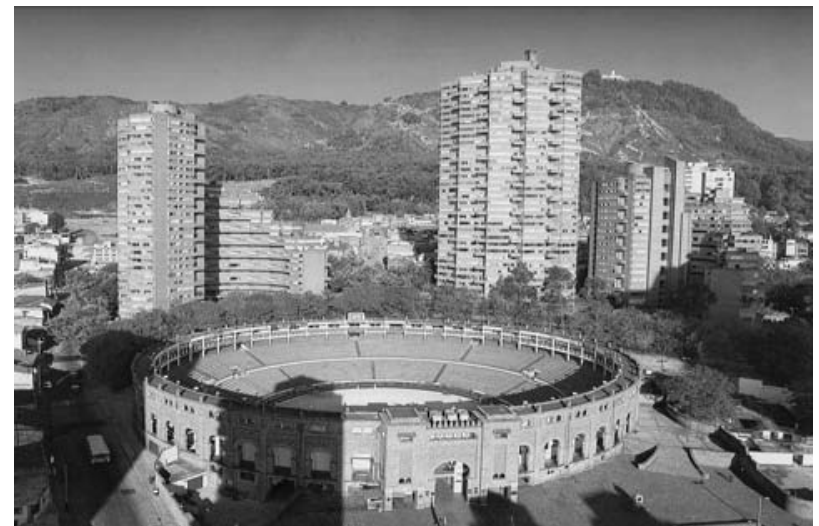

Figura 4.- Vista de la Plaza de Toros neomudejar de Bogotá en primer plano, con 2 de las Torres del Parque de Salmona.
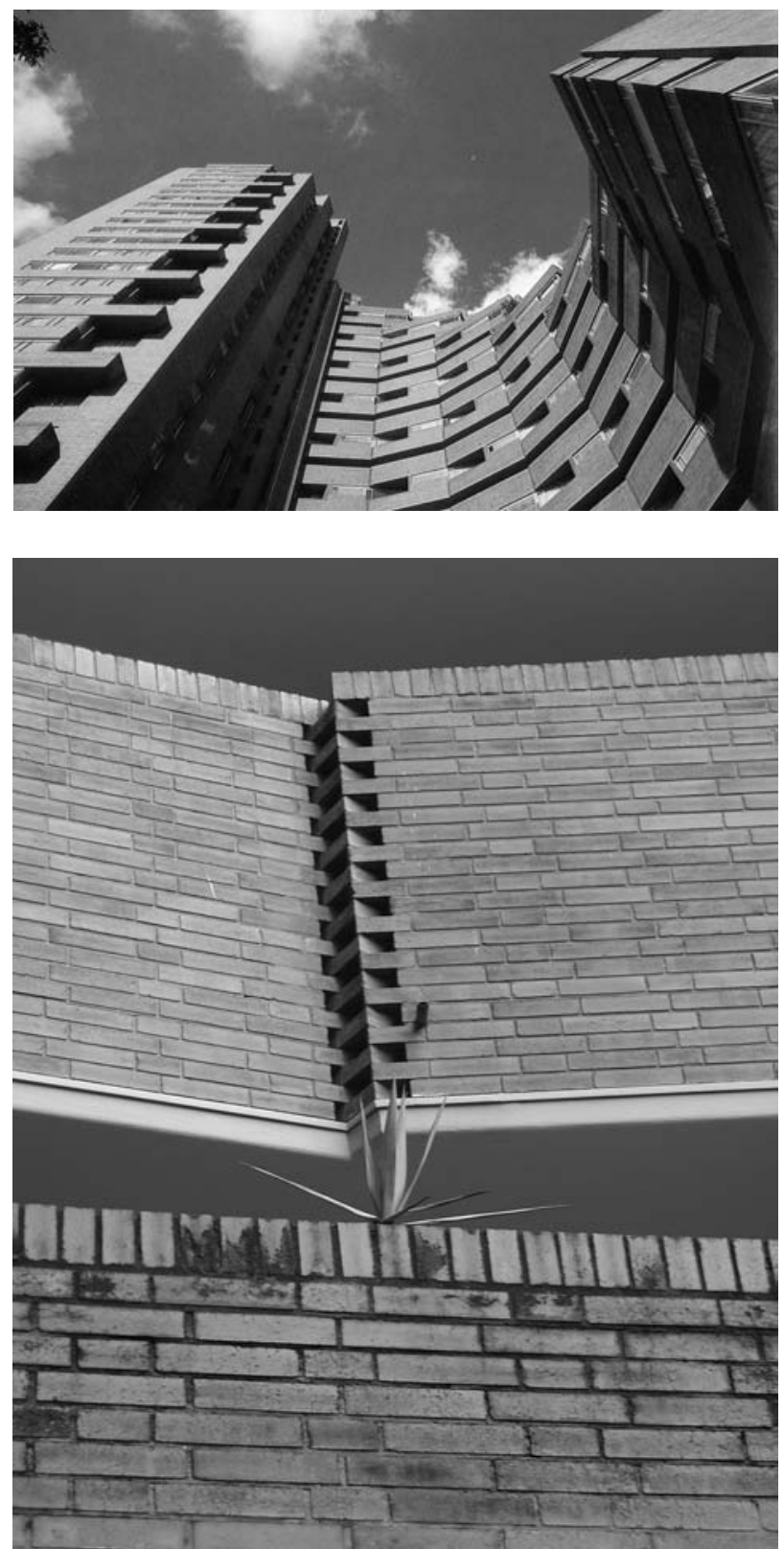

Figura 5.- a) Conjunto de la fachada cóncava de las Torres del Parque; b) Encadenado visto de los paños de ladrillo articulados entre sí.

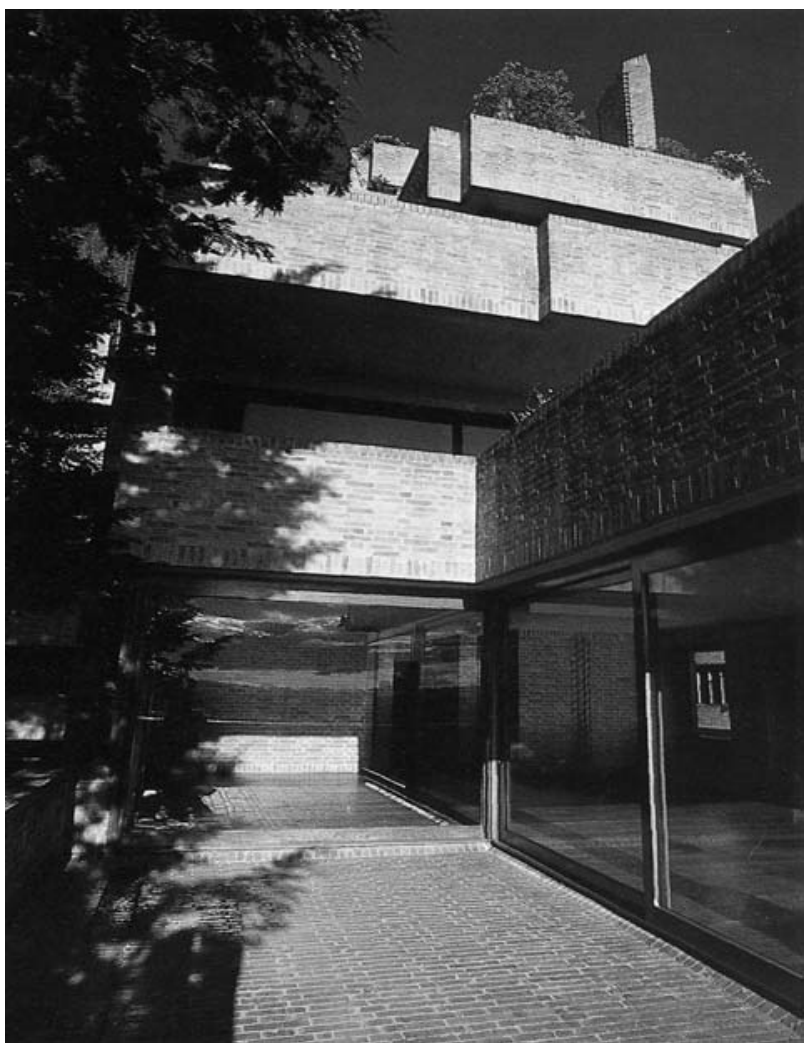

Figura 6.- Paños de Alto de los Pinos con remate inferior a sardinel de canto chapando el frente del forjado y vierteaguas superior a sardinel.

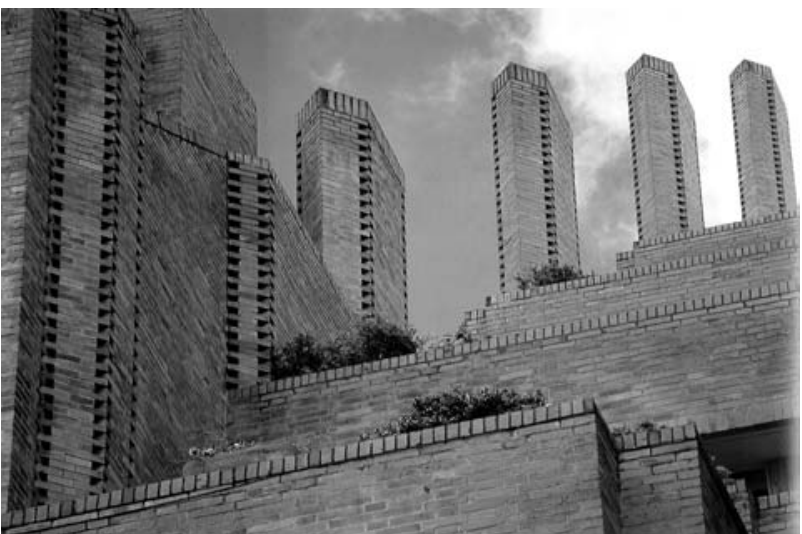

Figura 7.- Chimeneas endentadas en las viviendas de Alto de los Pinos (1976).

Posteriormente, en el conjunto residencial Alto de los Pinos (1976), Salmona conforma ya los voladizos de las viviendas escalonadas en la ladera en pendiente de más de $45^{\circ}$, terminando los paños de fábrica con remate inferior a sardinel de canto, chapando el frente del forjado, y vierteaguas superior a sardinel (Fig. 6).

En este edificio lleva a su máxima expresión el endentado de articulación planteado en los paños de las Torres del Parque, hasta conformar el característico enhebrado que define las chimeneas del Alto de los Pinos (Fig. 7). 


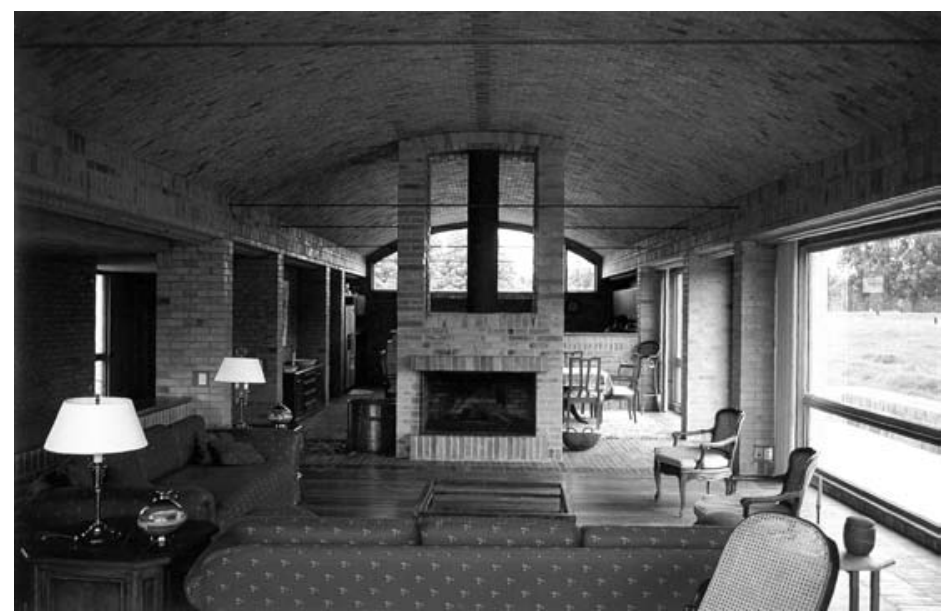

Figura 8.- Bóvedas de ladrillo atirantadas en el interior de la Casa Tenjo en La Sabana (1989).

Es interesante observar el entendimiento casi directo que Salmona hace de la interpretación de las bóvedas tabicadas que en 1928 hizo Le Corbusier, cuando viajó a Cataluña, y dibujó las Escuelas de la Sagrada Familia de Gaudí, junto a otras bóvedas tabicadas, para después reinterpretar esta técnica constructiva en las bóvedas atirantadas de la Casa Jaoul en París (1955) con los ladrillos dispuestos de plano sin aparejar.

En las casas de la Sabana, y concretamente en la Casa Tenjo (1989), Rogelio Salmona recurre a las bóvedas de ladrillo rebajadas y atirantadas, para conformar los espacios habitables (Fig. 8).

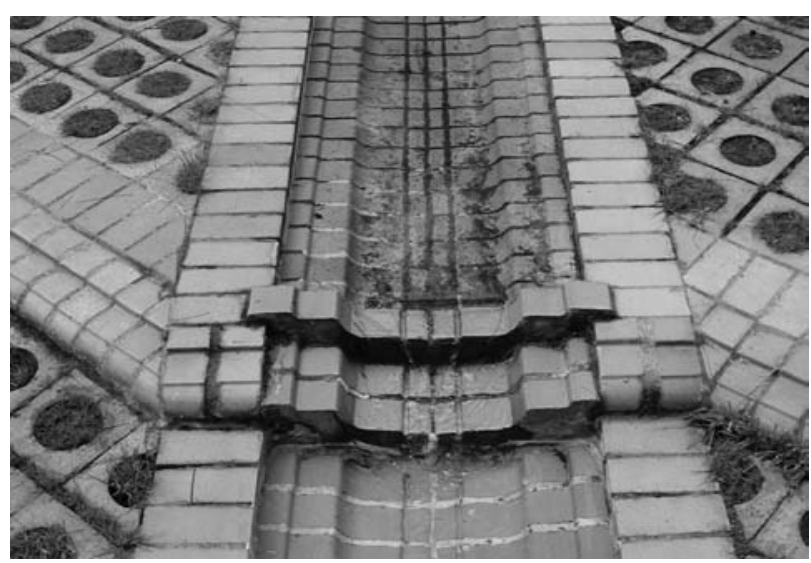

Figura 9.- Detalle de conducción de agua al aire y recogida de lluvias

En los patios, entre los espacios, existe una cuidada recogida de aguas, que se convierte, a su vez, en recorridas al aire, convenientemente rematados con piezas cerámicas (Fig. 9)

\section{LOS EDIFICIOS PÚBLICOS}

En la Casa de Huéspedes (1978), Salmona, retoma de forma similar a como hace en las viviendas anteriores, la sucesión de arcos de bóvedas tabicadas, rebajadas y atirantadas con ladrillo, aplicadas sobre vigas de hormigón armado que apoyan sobre muros de piedra, si bien en este caso disponiendo dos roscas de ladrillo de canto y aparejado, tal como demuestra el detalle constructivo del autor empleando ladrillo "tolete" prensado de $0,55 \times 0,12 \times 0,24$ colocado de canto en dos roscas (Fig. 10).

Se trata de la rehabilitación y ampliación de las ruinas del Fuerte de San Juan de Manzanillo (s.XVII), situado en la Bahía de Cartagena de Indias, transformando la edificación de la época colonial, en Casa de Huéspedes Ilustres de Colombia (Fig. 11).

En esta obra destaca también la incorporación de fuentes, con recorridos de agua por acequias y embalses, que

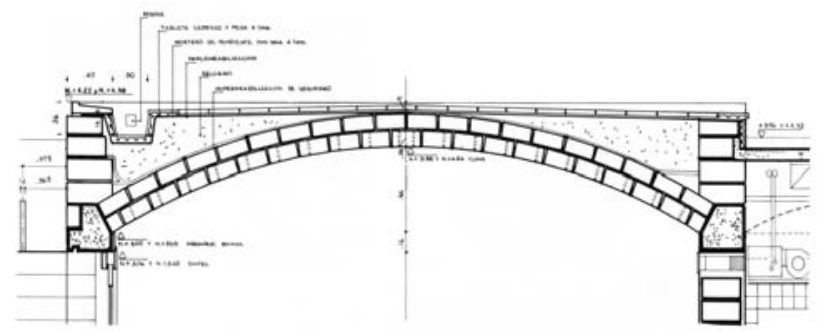

Figura 10.- Detalle constructivo de la bóveda de la Casa de Huéspedes, donde se aprecia el ladrillo empleado en las roscas.

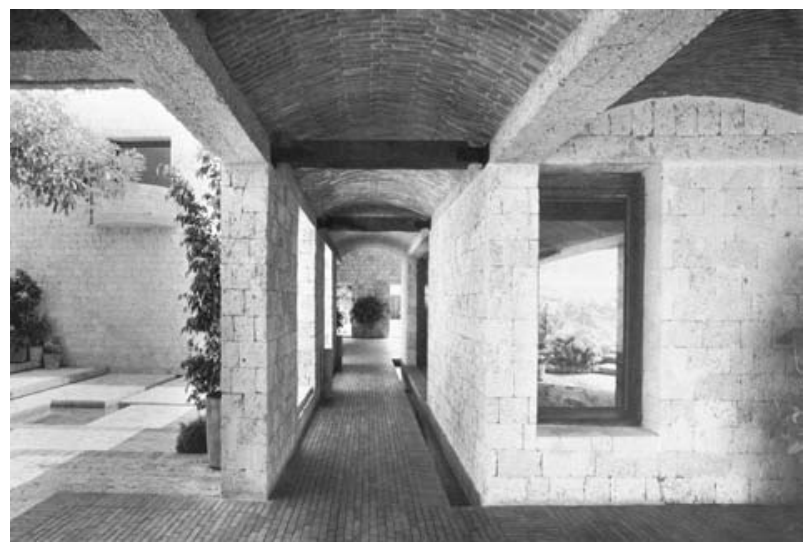

Figura 11.- Vista de los espacios de la Casa de Huéspedes construida en piedra y con bóvedas atirantadas. 
ambientan los espacios públicos, y que retoman los jardines del Generalife de la Alhambra.

Donde Rogelio Salmona da un salto cualitativo en el cuidado del empleo del ladrillo, es en su obra más significativa del Archivo General de la Nación (1988-1992).

La planta del Archivo General denota una clara inspiración en el Arquitecto norteamericano Louis Kahn, sobre todo en los encuentros de las esquinas del edificio y alberga un patio circular central envuelto en un recinto cuadrado que se abre hacia la Iglesia del Carmen del Cerro de Monserrate (Fig. 12).

En esta obra destaca la claridad compositiva de sus fachadas donde se emplean con profusión los huecos cuadrados que, en ocasiones, están velados con celosías caladas de ladrillo para lo que Salmona ha diseñado una pieza aplantillada de bordes redondeados, o pieza jamba (Fig. 13) [ver Fig. 16].

En esta obra Rogelio Salmona cuida mucho el remate perimetral de los huecos, para lo que ha desarrollado una pieza aplantillada prensada de sección escalonada que le permite rematar las jambas así como el vierteaguas del antepecho y la parte inferior de los dinteles, generando con ello un suave recercado escalonado en los huecos cuadrados de este edificio con la pieza dintel (Fig. 14) [ver Fig. 16].

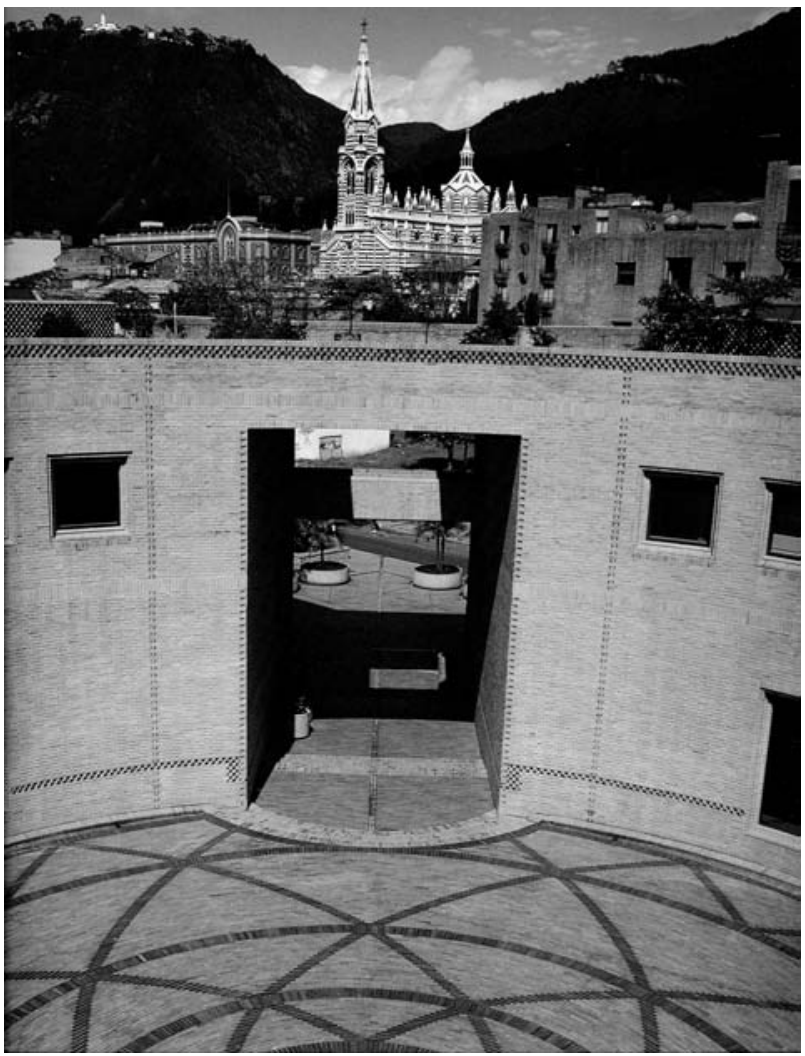

Figura 12.- Vista desde el patio interior circular del Archivo General, a la Iglesia del Carmen y el Cerro de Monserrate.

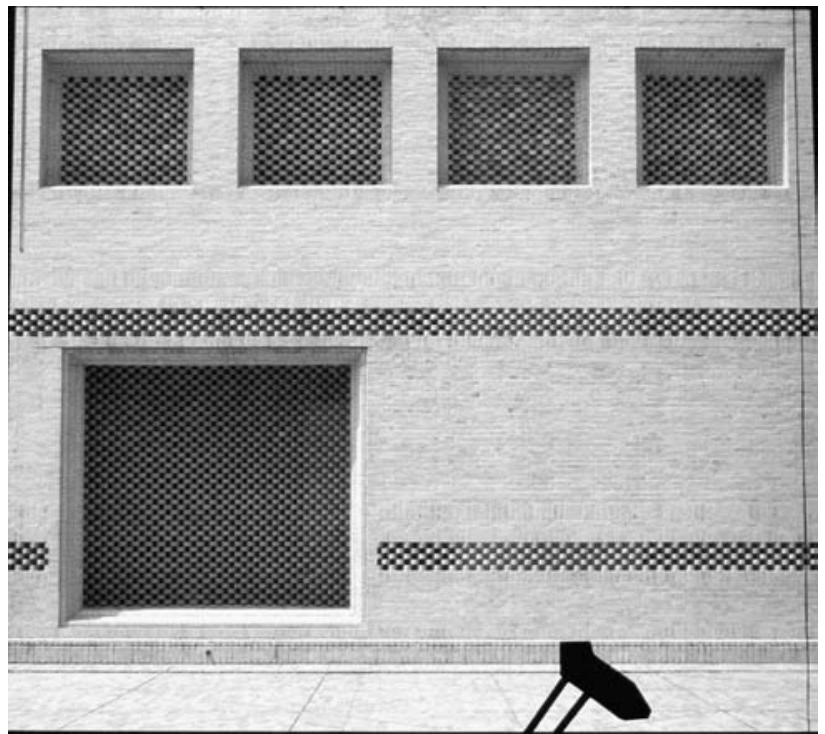

Figura 13.- Vista de la fachada opuesta desde el interior, con huecos cuadrados tratados con celosías, las cuales se emplean también en bandas.

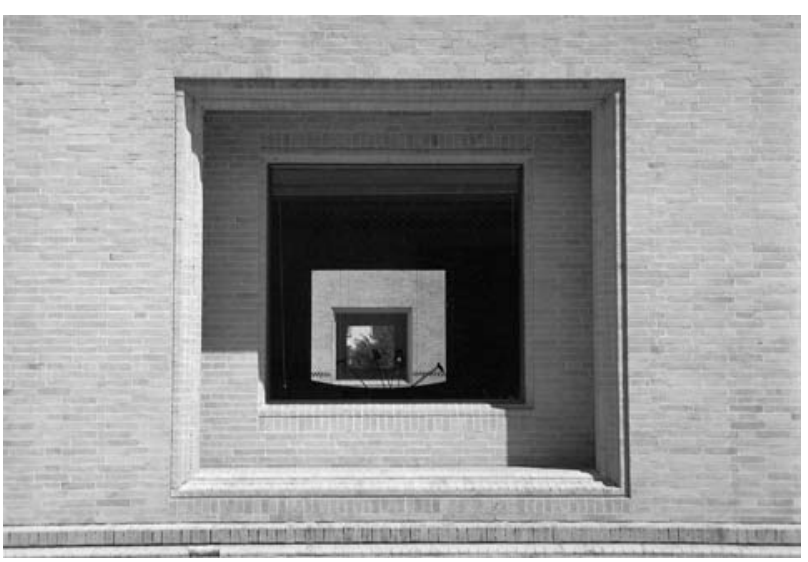

Figura 14.- Vista desde el exterior, del espacio interior a través de los huecos cuadrados entre patios con huecos recercados de ladrillo aplantillado.

Una de las últimas obras, todavía inconclusa, es el Museo de Arte Moderno de Bogotá (1971-1979), donde el autor amplía las proporciones del hormigón armado frente al ladrillo.

\section{PECULIARIDADES CONSTRUCTIVAS EN LA- DRILLO}

La construcción de las fábricas de los edificios de Salmona se caracteriza por emplear siempre 1 pie de ladrillo aparejado [ver Fig. 5].

El aparejo empleado es muy característico del autor, y consiste en combinar una hilada impar a soga, con otra par a soga y tizón, de tal manera que el solape entre unas 


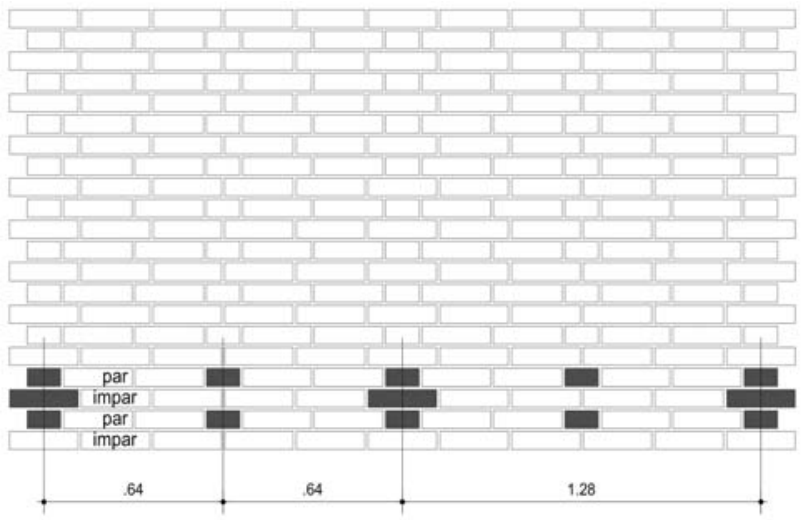

Figura 15.- Aparejo característico de una fábrica de ladrillo de Rogelio Salmona para unas viviendas.
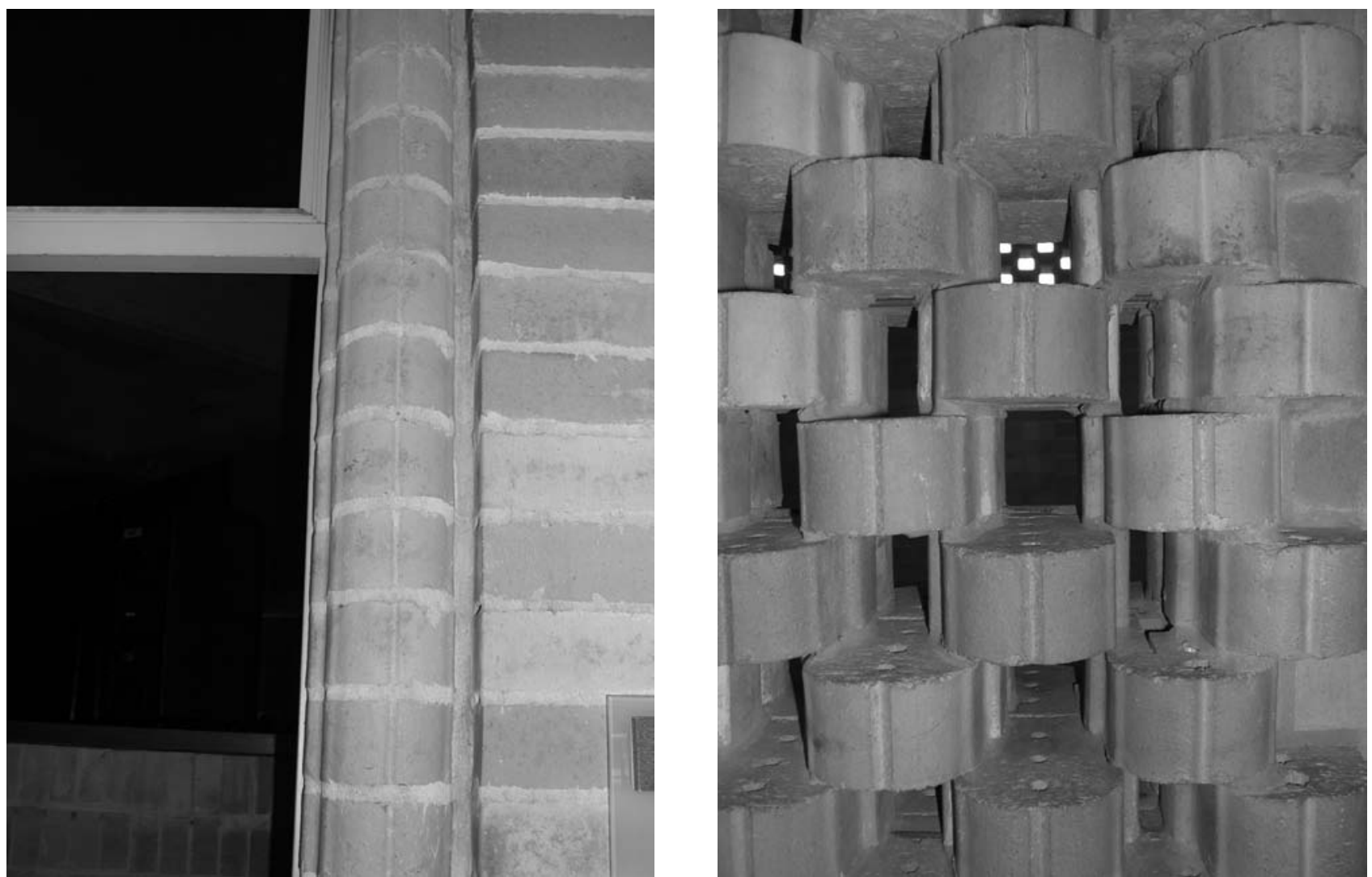

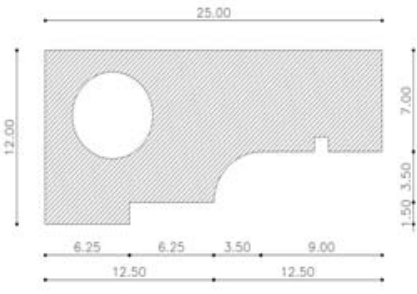

PIEZA DINTEL

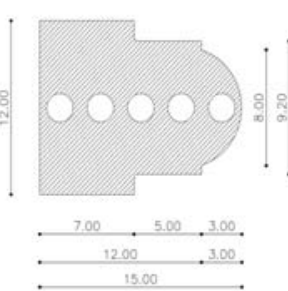

PIEZA JAMBA
Figura 16.- Detalle de las piezas jamba y vierteaguas, diseñadas por Rogelio Salmona para unas viviendas.

Figura 17.- a) Pieza jamba en su ubicación habitual; b) Pieza jamba conformando una celosía calada.

piezas y otras, es de $1 / 4$ de ladrillo, quedando el conjunto del paño de fábrica con una secuencia de rombos verticales que se manifiestan cada 4 sogas en horizontal entre los que quedan, de forma centrada, las piezas a tizón que alternativamente atan las dos hojas entre sí (Fig. 15) [ver Fig. 14].

La construcción de muros de 1 pie de grueso, le permite apoyar cómodamente $2 / 3$ de su grueso sobre el borde del forjado, y sobrevolar 1/3 del largo del ladrillo para chapar 

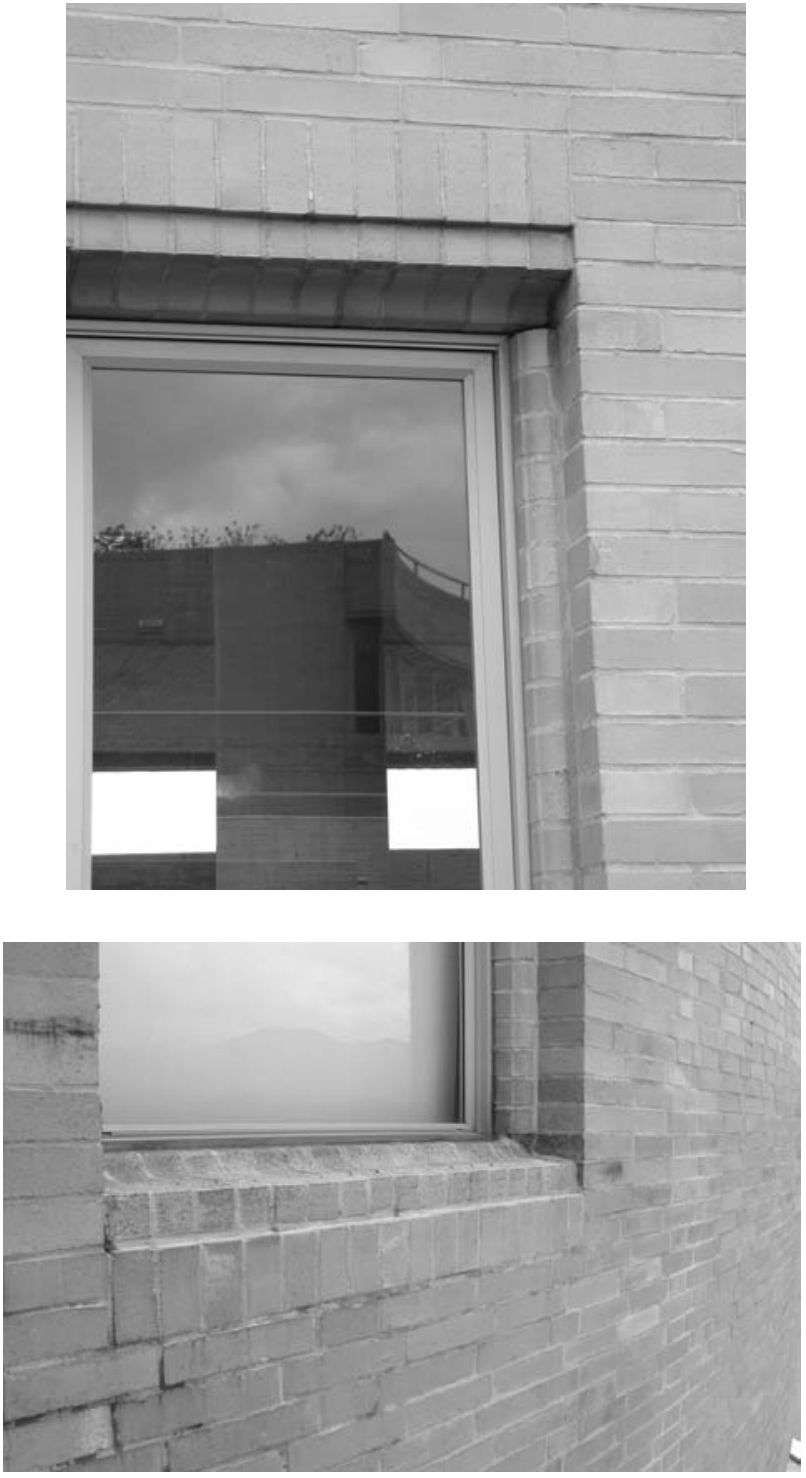

Figura 18.- a) Pieza dintel en su ubicación habitual; b) Pieza dintel dispuesta a modo de vierteaguas.

Hasta tal punto le interesa ese efecto a Salmona, que en ocasiones dispone la pieza de jamba en el centro del paño, para crear la sensación anterior, cuando, de hecho, no se trata de ningún encuentro entre paños, o bien para componer con un encuentro de esas características [ver Fig. 12].

Las piezas diseñadas por Salmona, tienen unas características geométricas definidas para conseguir los remates apropiados para muros de 1 pie de grueso, con la carpintería intermedia, lo que difícilmente les permite adaptarse adecuadamente a muros de $1 / 2$ pie. Con sólo este par de piezas especiales, la pieza jamba y la pieza vierteaguas, el Arquitecto es capaz de conformar los distintos remates de la mayoría de sus edificaciones (Fig. 16).

La pieza de jamba de bordes redondeados, la utiliza Salmona para dar continuidad formal al perímetro lateral del hueco, apilándola en vertical (Fig. 17.a).
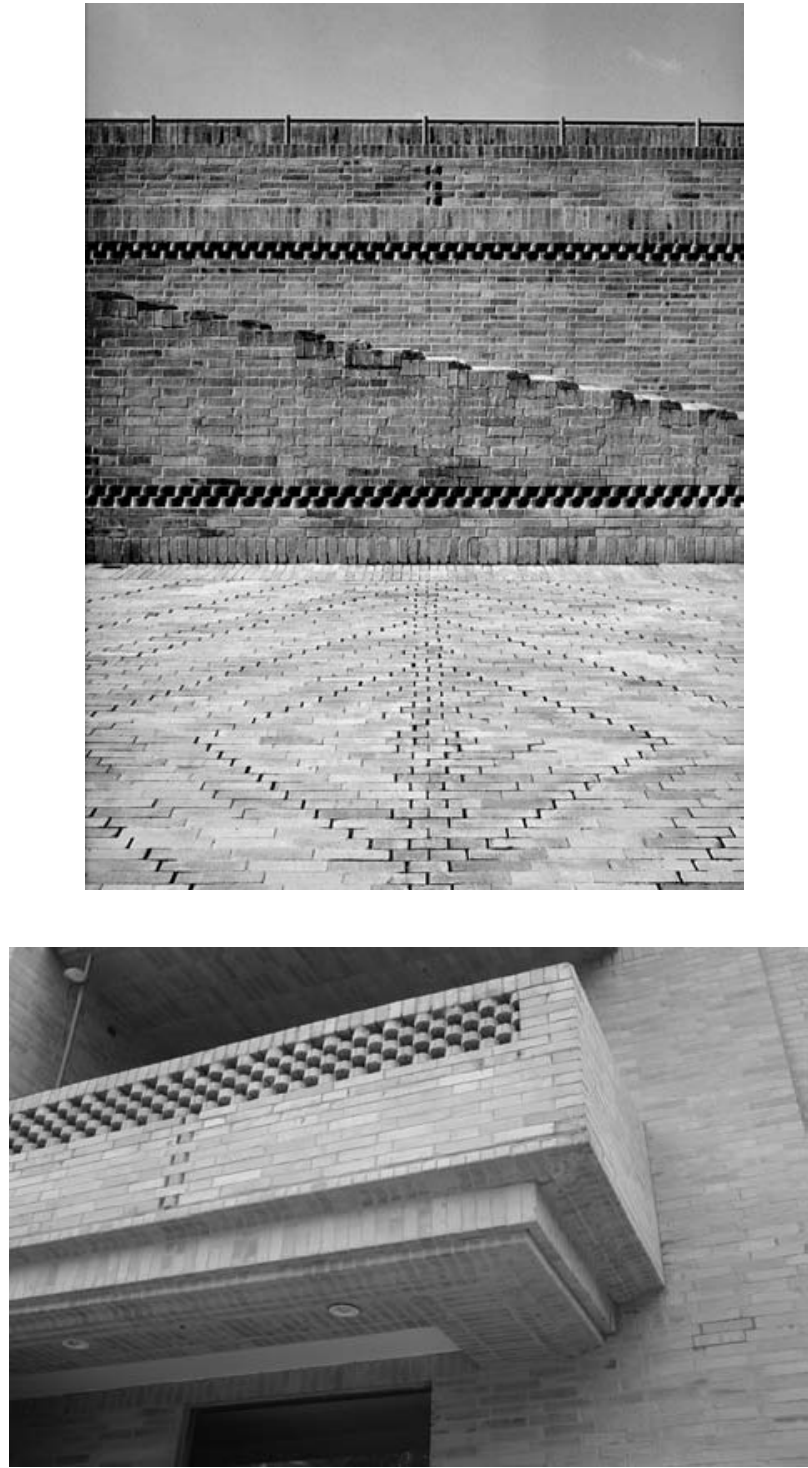

Figura 19.- a) Pieza dintel coronando un peto de barandilla; b) Pieza dintel revistiendo la parte inferior de una terraza.

Con dos piezas de jamba dispuestas contrapuestas en un muro de 1 pie de grueso, para mantener así la cara curva a la vista en ambos frentes, y alternando su posición en las hiladas sucesivas, consigue crear una celosía aparente por ambas caras y con huecos entre ella suficientemente calados y profundos para generar las sombras apropiadas, quedando al tiempo el hueco deseado para ventilar la climatología húmeda del país (Fig. 17.b.) [ver Fig. 13].

La pieza dintel la emplea Salmona profusamente junto con su variante invertida a modo de vierteaguas, logrando, con su escalonado redondeado, el desagüe de la lluvia (Fig. 18.a y b.). Este planteamiento lo repite sucesivamente en otras partes de la edificación. Así pues la pieza dintel puede prolongarse por debajo del vuelo de los balcones, mientras que la misma pieza, a modo de vierteaguas, le sirve para coronar las rampas o escaleras (Fig. 19.a y b.). 


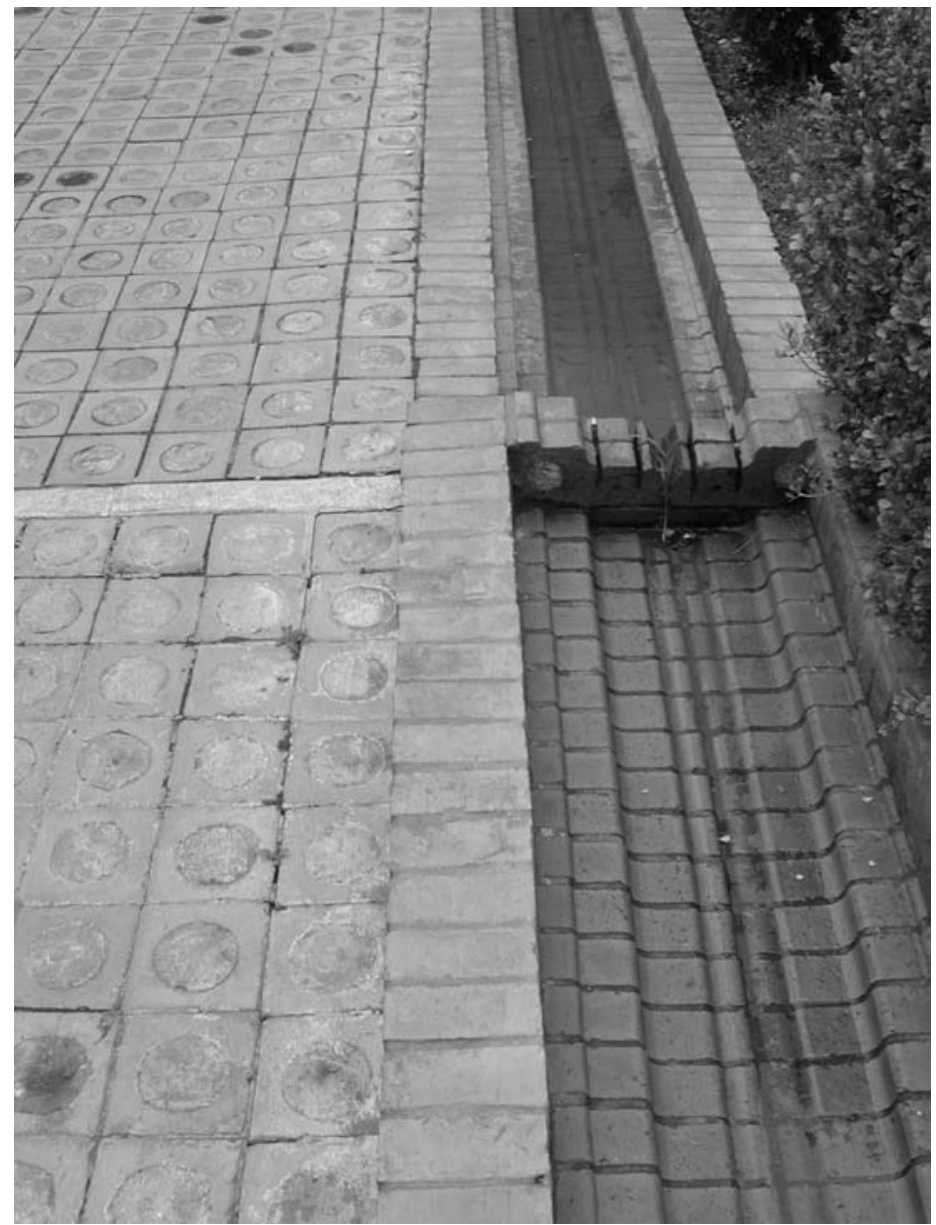

Figura 20.- Dos piezas dintel dispuestas a modo de vierteaguas y enfrentadas, para canalizar el agua, junto a pavimento cerámico perforado rellenado de hormigón, para el paso, y de césped para el ajardinado.

En los tratamientos de los suelos, Salmona se esmera en no dejar ninguna zona sin tratar, alternando, en muchas ocasiones, juegos ornamentales con ladrillo, como el de inspiración helicoidal renacentista [ver Fig. 12], con acequias que conducen el agua y refrescan el ambiente, al tiempo que le permite desaguar las lluvias a través de ellas (Fig. 20).

No hay que olvidar que toda esta tecnología constructiva, en determinadas zonas, se surte de anclajes metálicos y/o angulares, cuando los petos o los dinteles lo requieren, lo que no queda a la vista en su arquitectura.

\section{AGRADECIMIENTOS}

El autor del artículo agradece la inestimable colaboración del Arquitecto Rogelio Salmona y su equipo de Arquitectos en España, J. M. Ezquiaga y A. Jaramillo, cuyas fotos de detalle han servido para ilustrar este artículo.

\section{BIBLIOGRAFÍA}

"Salmona". Ricardo L. Castro. Ed. Villegas Editores. Bogotá, Colombia, 1998.

"Rogelio Salmona. Arquitectura y poética del lugar". Colección SomoSur. Facultad de Arquitectura Universidad de los Andes. Bogotá, Colombia 1991. 